\title{
ESTIMATING LEARNING ASSISTANCE SKILLS USING LEARNING ANALYTICS
}

\author{
Hiroyuki Watanabe ${ }^{1}$, Yoshiko Goda ${ }^{2}$, Atsushi Shimada ${ }^{3}$ and Masanori Yamada ${ }^{4}$ \\ 1Faculty of Arts and Science, Kyushu University, 744, Motooka, Nishi-ku, Fukuoka 819-0395, Japan \\ 2Research Center for Instructional Systems, Kumamoto University, 2-39-1, Kurokami, Chuo-ku, Kumamoto, \\ 860-0862, Japan \\ 3Faculty of Information Science and Electrical Engineering, Kyushu University, 744, Motooka, Nishi-ku, \\ Fukuoka 819-0395, Japan \\ 4Faculty of Arts and Science, Kyushu University, 744, Motooka, Nishi-ku, Fukuoka 819-0395, Japan
}

\begin{abstract}
Learning assistance is an essential part of higher education. Tutors, the core of the assistance staff, need to have learning assistance skills. If the potential for these skills can be identified when selecting tutors, the training method will be more efficient. Also, learning assistance skills are thought to be related to learning skills. Therefore, in this paper, we used previous research to identify the relationship between learning skills and learning assistance skills to clarify this. Then, using learning analytics, we explored whether learning support skills can be determined from learning skills.
\end{abstract}

\section{KEYWORDS}

Learning Skills, Learning Assistance Skills, Learning Analytics, CRLA, ITTPC

\section{INTRODUCTION}

Lack of student preparation for college is not a new phenomenon in higher education in the United States (US) (Sheets 1994). Therefore, "widely used academic support programs aimed at improving student retention and persistence rates (Brooks 2006)" have become indispensable. Among them, tutoring has become a standard service in the ongoing support for students to graduate (Colver and Fray 2015).

The programs cover topics such as textbook reading, time management, effective note-taking, use of resources such as libraries, and preparation for exams (Wernersbach et al. 2014). Learning assistants are also often referred to as peer tutors in the US (Maxwell 1997). Peer tutors provide course-specific content and study skills to support undergraduate students across the curriculum (Keller 2020). It can also refer to the various ways in which learning takes place through interaction with peers (Rae and Baillie 2005).

One of the reasons for the recent increase in peer tutoring in universities is the decreasing resources and increasing student numbers. In other words, there is a growing interest in peer tutoring as a means of doing more with less, while improving the quality of education (Topping 1996). Maxwell surveyed the literature on tutoring in 1990 and noted that training of peer tutors was essential to the success of tutoring programs in universities (Maxwell 1990).

Thus, learning assistants have to be trained. The training method will be more efficient with the information on their potency for learning assistance skills when selecting them. Of course, the higher the potential, the more advanced will be the learning and the more competent they will be as learning assistants. As a way to measure the potential, it is desirable to understand whether the learning skills of students, the possible learning assistants, are sufficient in their usual study.

Therefore, in this study, based on the review of learning assistance skills, the relationship with learning skills will be discussed. Moreover, based on the analysis of recent learning behavior, we will explore the possibility of estimating the degree of learning assistance skills using learning analytics (Schumacher and Ifenthaler, 2018), which aims to improve the learning environment. 


\section{PREVIOUS RESEARCH REVIEW}

\subsection{Learning Assistance Skills from the Perspective of Learning Assistance Programs}

Many universities are now adopting various programs to help students adapt and succeed in higher education.

These programs focus on topics such as time management, reading textbooks, taking effective notes, using resources such as the library, and exam preparation. The study also found that students enrolled in study skills courses initially had lower levels of self-efficacy. However, after testing, they reached levels equal to or higher than those of comparison students (Wernersbach et al. 2014).

Moreover, success courses for university students are designed to help develop effective self-regulated learning (SRL) skills. Therefore, students believed that time management and motivation are important for becoming effective college students (Hoops, 2016). Similarly, in the case of distance education, study skills, motivation, time management, exam preparation, and coping with exam stress affect students' success (Poyraz 2013).

Next, regarding programs and their effectiveness, Dakhiel et al. (2019) found the effectiveness of training programs in developing study skills and improving the English language proficiency of 10th grade students. To examine learning skills, the students were classified into five independent sub-skills according to the list developed by Dennis (2010). According to this list, these were procedurally defined as grades in each skill (i.e., textbook, memory, test preparation, concentration, and time management skills).

O'Reilly and Sabatini (2016) introduced a cognitive science intervention for students who struggled with reading, and Salame and Thompson (2020) found that methodical note-taking can benefit students by providing a specific way of learning and help them perform better in their courses. They also said that there is a correlation between note-taking and grade point average (GPA) of students as those who are good note-takers also have a higher GPA. Akkaraju (2018) stated that writing by hand is a multisensory process that enhances learners' memory, concentration, focus, and cognition, making it a valuable learning skill.

Along with the effectiveness of mutual learning, Stigmar (2016) analyzed how tutors and tutees benefited from peer teaching. The most common research design was the use of quasi-experimental pre- and post-tests. The main educational beliefs and theories are social constructivism. The main conclusion was that generic skills development and metacognitive training benefited from peer teaching. It has also been shown to have positive effects on student tutors and tutees (Keller 2020).

Wolfe (2018) investigated the impact of a peer tutoring model in information technology foundations (ITF), an introductory computer science course at a high school in South Carolina. The results showed improved post-test scores, increased completion of assignments, lesser time spent waiting for support when there was confusion, and improved cooperative learning skills as students had to learn to communicate in a meaningful way while respecting each other. Reporting that student participants benefited in various ways, Yaman (2019) examined the characteristics of peer tutoring in a first-year engineering calculus I course and found that tutors and tutees had three types of relationships that depended on the skills of the tutor and peer personality (interdependent, mutual support, and tutoring).

Thus, learning assistance programs include topics such as SRL, time management, note-taking, reading, and exam preparation which are effective for tutors and tutees in terms of mutual and cooperative learning. However, the boundary between them and learning skills is not clear. Therefore, in the next section, we will approach the issue from the perspective of the skills needed by peer tutors and learning supporters.

\subsection{Standards for Learning Assistance Programs by CRLA}

In the 1980s, several national associations for professionals in the learning assistance field emerged. This was because of the rapid increase in the number of faculty and learning assistance centers. Training tutors created a need for a new category of staff to work in universities and to provide a forum for them to discuss their professional development with colleagues and experienced leaders in learning assistance (Colver and Fry 2016). College Reading and Learning Association (CRLA; https://www.crla.net/index.php/membership/ about-us) is one of the organizations that emerged from this process. It was here that the International Tutor Training Program Certification (ITTPC), announced in 1986 to certify the quality of tutor training programs, 
was considered. The concept was developed over three years and became the CRLA's ITTPC (originally ITCP) in 1989 (Sheets 2012). Today, certification for tutor training programs is more widely recognized as a means of providing consistent and quality learning support. The ITTPC sets the standard for tutor training.

This program is divided into levels one to three according to the skills and experience of the tutors. The ITTPC is unique as it does not certify individual tutors, but the institutions that train them. Since 1989, more than 1,000 university tutor training programs around the world have taken the ITTPC at one or more levels, and thousands of people from these programs have been certified as tutors, advanced tutors, or master tutors. Table 1 shows the items required at Level 1 of the ITTPC.

Table 1. ITTPC Topics (Level 1)

\begin{tabular}{|c|l|l|}
\hline No. & \multicolumn{1}{|c|}{ Topics } & \multicolumn{1}{|c|}{ Learning skills } \\
\hline 1 & Definition of tutoring and tutor responsibilities & No relations \\
\hline 2 & Basic tutoring Guidelines/ Tutoring Do's \& Don'ts & No relations \\
\hline 3 & Techniques for beginning and ending a tutoring session & No relations \\
\hline 4 & Adult learners and/or learning theory and/or learning styles. & No relations \\
\hline 5 & Assertiveness and/or Handling Difficult Situations. & No relations \\
\hline 6 & Role Modeling & \multicolumn{1}{|c|}{ Relations } \\
\hline 7 & Setting Goals and/or Planning \\
\hline 8 & Communication Skills & No relations \\
\hline 9 & Active Listening and Paraphrasing & No relations \\
\hline 10 & Referral Skills & No relations \\
\hline 11 & Study Skills & Relations \\
\hline 12 & Critical Thinking Skills & No relations \\
\hline 13 & $\begin{array}{l}\text { Compliance with Ethics and Philosophy of the Tutoring Profession \&/or } \\
\text { Compliance with Sexual Harassment concerns \&/or Compliance with }\end{array}$ & No relations \\
\hline 14 & Plagiarism concerns. & No relations \\
\hline
\end{tabular}

\subsection{Relationship between Learning and Learning Assistance Skills}

Learning assistance skills were discussed in sections 2.1 and 2.2, and their relationship with learning skills will be summarized here. Learning analytics captures and analyzes the learning behavior of individuals, and although it is possible to estimate learning skills, it is difficult to trace the behavior that supports others' learning from the learning behavior. Therefore, to estimate whether an individual has learning support skills, we analyzed if learning skills were strongly related to the support skills.

We will now discuss ITTPC's Topic 6,7, and 11, which we believe are related to learning skills.

First, "Topic 6: Role Modeling" is based on the criteria such as being a role model for learners, using a calendar to make appointments and take notes, practicing specific learning methods, creating a personal schedule that supports sufficient study time, and communicating with faculty (through email and face-to-face). In other words, it is related to an important aspect of learning skills, time management. This shows that students can create a schedule that takes into account their fixed schedule, classes, and study time, and create a study plan before the final exam period.

Next, "Topic 7: Setting Goals and/or Planning " means that tutors can effectively help learners plan and set their personal academic goals according to the criteria set in the tutor training. This corresponds to time management study skills. If students do this type of time management, it is possible to help them.

The last topic, "Topic 11: Study Skills," states that tutors develop a repertoire of effective study skills and strategies to facilitate the learning of new information (e.g., effective time management, organization, note-taking, test-taking, motivation, mastery, retention, performance, and reducing anxiety), which is a learning skill.

The above three topics are the ones that overlap with learning skills, and if these can be estimated from the logs, it may be possible to estimate learning support skills indirectly. 


\section{CAN LEARNING ANALYTICS BE USED TO ESTIMATE LEARNING ASSISTANCE SKILLS?}

Recent advances in Information and Communication Technology (ICT) have made it possible to trace the behavior of learners using the learning analytics approach. Watanabe et al. (2020a) organized the learning skills that can be traced by the LA approach, focusing on the types of learning behaviors, especially lecture-style classes in educational institutions. The systems used here include e-book viewers (Teasley 2017) and learning management systems (LMS). Moreover, a personalized learning analytics dashboard (LAD) for students was developed by integrating data from a student information system into a basic algorithm (Ogata et al. 2017, Chen et al. 2019, Lu et al. 2020). The LAD can visualize information about the acquisition and use of learning skills. Chen et al. (2020a) listed two effects of LAD: "First, students' perceptions of visual attraction for LAD assessment and learning behaviors were related to reflection." "Second, the students' perceptions of behavioral changes for LAD had positive effects on the regulation of cognition dimension." Moreover, Chen et al. (2021) identified (1) appropriate graphic representations; (2) comparison functions; (3) monitoring functions that relate to goal attainment; and (4) consistent feedback" as four important elements of LAD.

At Kyushu University, as specific tools, the LADs used are Real-time Monitoring (Figure1)(Shimada et al. 2018, Owatari et al.2020), Reading Path (Figure 2)(Chen et al.2019, Lu et al. 2020), and MAI Helper (Figure 3) (Watanabe et al. 2021). What kind of learning skills can be estimated by the LA approach?

First, the real-time monitoring shows the markers and words that students are paying attention to in BookRoll, an e-book viewer, and whether they are pressing the "Get it" or "Not Get it" button on each page. This allows the log to show trends about reading for learning skills.

Second, for the reading path, the log shows which pages were viewed during and after the reading class, and how often they were viewed. This also falls under the learning skill reading.

Finally, there is the MAI Helper. This is a system that allows you to list your learning activities, which mainly applies to learning skills related to time management (Watanabe et al. 2020b). It also has memo, reflection, and calendar functions. Thus, using the system's logs, we can check time management, note-taking, reflection, access time, and frequency, all of which are related to learning skills. The system helps students develop study attitudes and habits by allowing them to manage their schedules. Table 2 shows an example of a student schedule $\log$. From these $\operatorname{logs}$, it is difficult to extrapolate learning assistance skills such as "tutor definition and tutor responsibilities," "techniques for starting and ending tutoring sessions," and "active listening and paraphrasing." Therefore, we believe that the basic learning skills of reading, writing, and time management can be estimated.We focused on the strategies of these from a pedagogical perspective. McNamana (2004) indicated that it helped students use logical thinking, or domain-general knowledge, rather than domain-specific knowledge, to understand the text. Palincsar and Brown (1984) showed that through reciprocal teaching, the quality of summarizing and questioning was greatly improved when tutors and learners took turns summarizing (self-reviewing), questioning, clarifying, and predicting the text. Furthermore, regarding time management by making plans and schedules for learning, Pintrich et al. (1993) mentioned that one of the self-regulated learning strategies is the resource management strategy, which includes "time management and environmental composition". Thus, students' basic learning skills are based on learning strategies such as "reading strategies", "writing strategies", and "self-regulated learning strategies". Estimating these basic learning skills can help instructors to understand how students' use their learning (assistance) skills, and to select students to lead group learning in the class, tutors for out-of-class activities. 


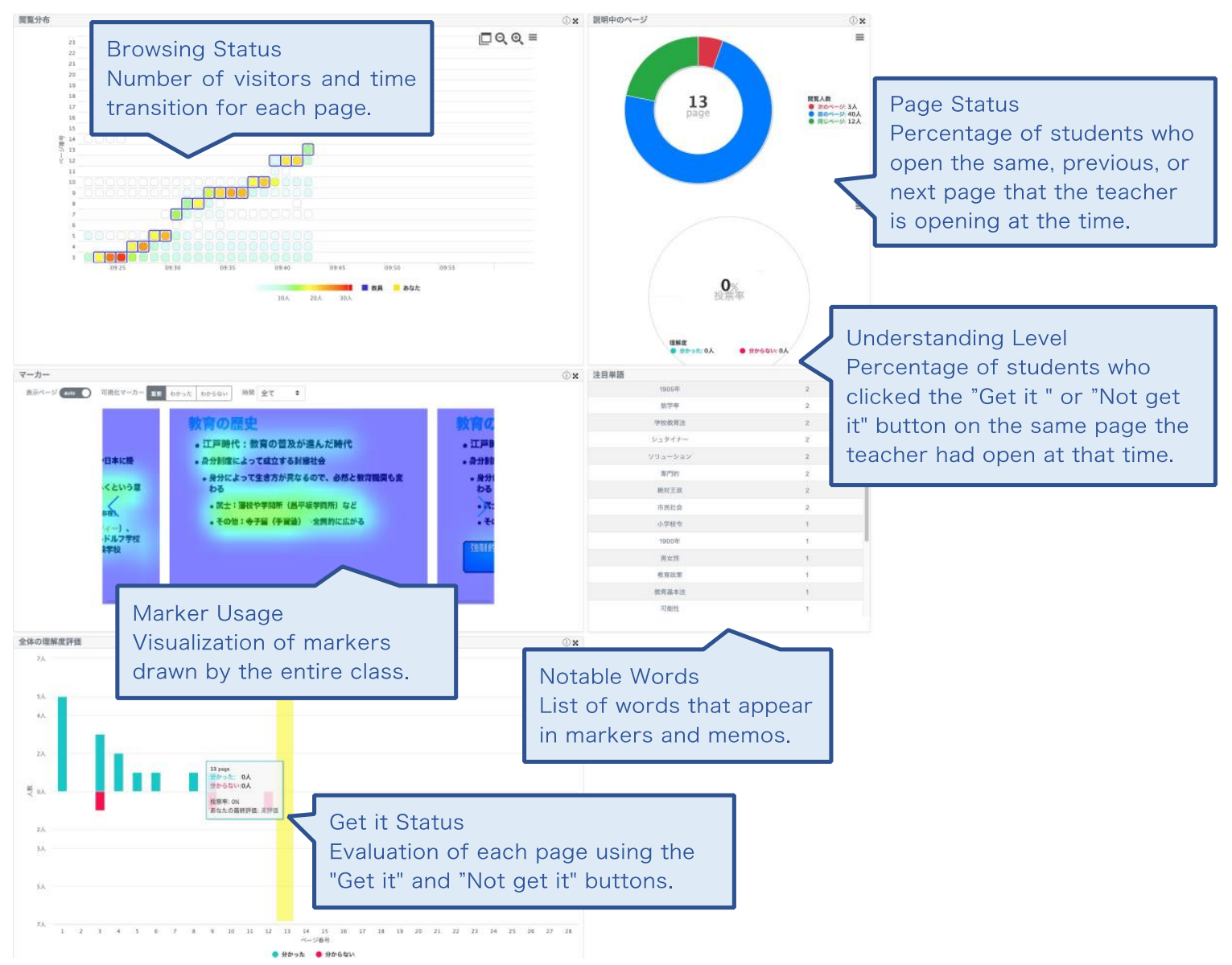

Figure 1. Real-time Monitoring overview

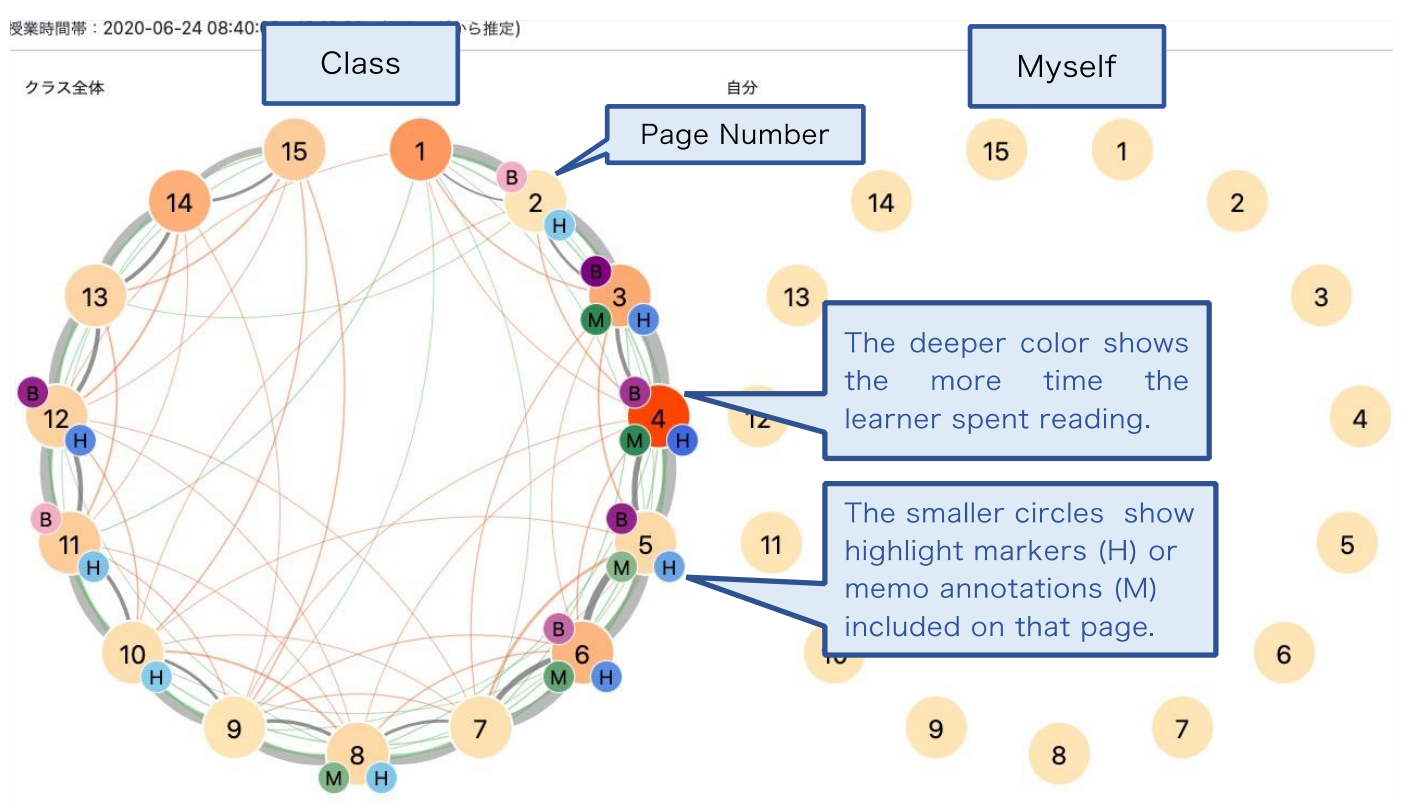

Figure 2. Reading Path overview of Metaboard 


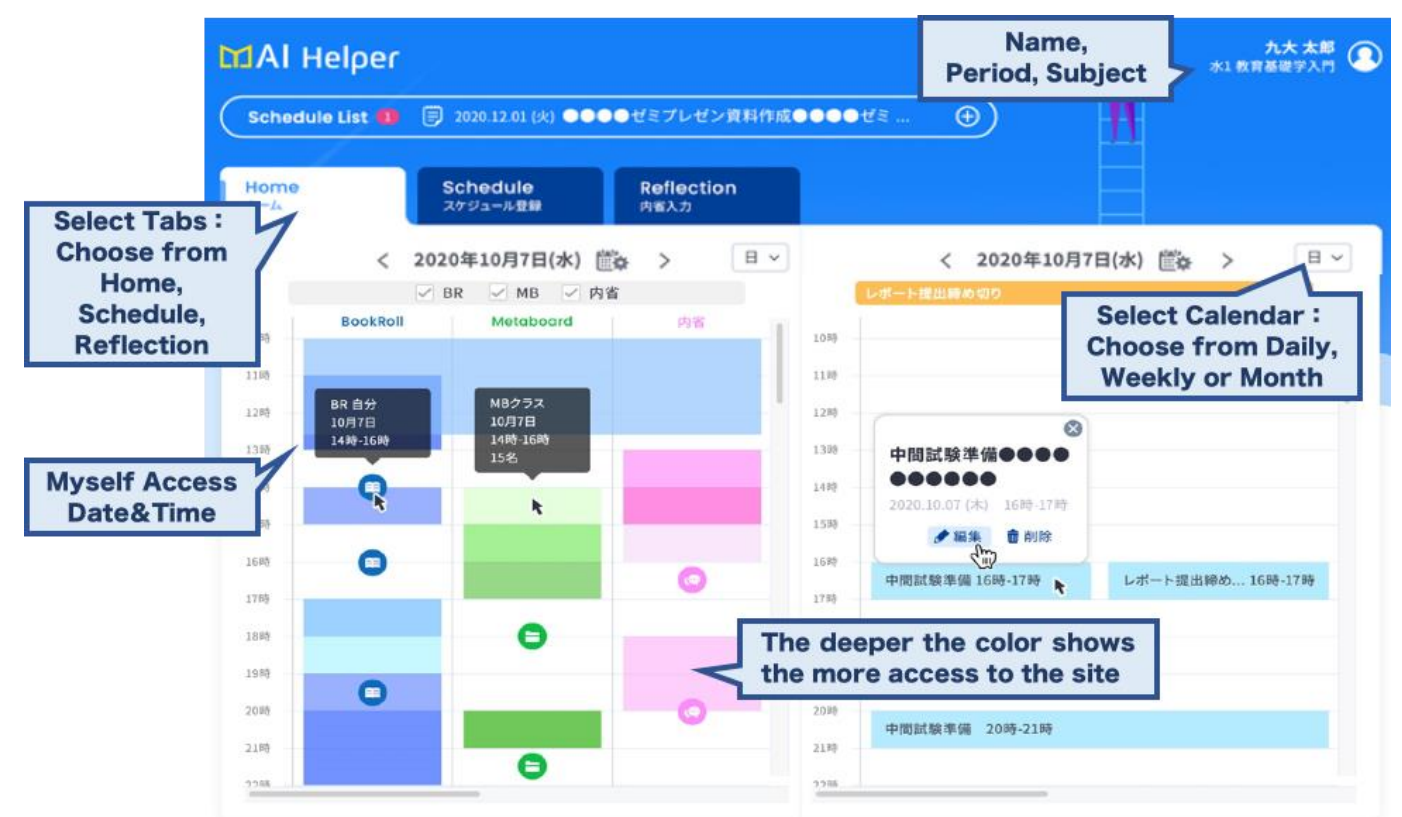

Figure 3. MAI Helper overview of Metaboard

Table 2. Example of Schedule Logs

\begin{tabular}{|c|c|c|c|c|c|c|c|c|}
\hline $\begin{array}{l}\text { Student } \\
\text { No. }\end{array}$ & Name & $\begin{array}{l}\text { Update } \\
\text { type }\end{array}$ & $\begin{array}{l}\text { Schedule } \\
\text { title }\end{array}$ & $\begin{array}{l}\text { Start } \\
\text { time }\end{array}$ & $\begin{array}{l}\text { End } \\
\text { time }\end{array}$ & $\begin{array}{l}\text { Repeat } \\
\text { setting } \\
\text { contents }\end{array}$ & $\begin{array}{l}\text { E-mail } \\
\text { notification } \\
\text { time }\end{array}$ & $\begin{array}{l}\text { Log } \\
\text { making } \\
\text { time }\end{array}$ \\
\hline 1375 & $\begin{array}{l}\text { Kyu } \\
\text { Taro }\end{array}$ & Addition & Test 1 & $\begin{array}{l}2021 / 1 / \\
1010: 00\end{array}$ & $\begin{array}{r}2021 / 1 / 10 \\
10: 10\end{array}$ & every day & $\begin{array}{r}2021 / 1 / 25 \\
10: 00\end{array}$ & $\begin{array}{l}2021 / 1 / \\
1010: 10\end{array}$ \\
\hline 1375 & $\begin{array}{l}\text { Kyu } \\
\text { Taro }\end{array}$ & Addition & Class & $\begin{array}{l}\text { 2021/1/ } \\
1213: 00\end{array}$ & $\begin{array}{r}2021 / 1 / 12 \\
14: 30\end{array}$ & every day & & $\begin{array}{l}2021 / 1 / \\
1214: 30\end{array}$ \\
\hline 1375 & $\begin{array}{l}\text { Kyu } \\
\text { Taro }\end{array}$ & Addition & Report & $\begin{array}{l}2021 / 1 / \\
2520: 00\end{array}$ & $\begin{array}{r}2021 / 1 / 25 \\
21: 30\end{array}$ & every day & $\begin{array}{r}2021 / 1 / 30 \\
10: 00\end{array}$ & $\begin{array}{l}\text { 2021/1/ } \\
2521: 30\end{array}$ \\
\hline 1375 & $\begin{array}{l}\text { Kyu } \\
\text { Taro }\end{array}$ & Addition & Library & $\begin{array}{r}2012 / 2 / \\
412: 00\end{array}$ & $\begin{array}{r}2012 / 2 / 4 \\
16: 30\end{array}$ & every day & & $\begin{array}{r}2012 / 2 / \\
416: 30\end{array}$ \\
\hline
\end{tabular}

\section{CONCLUSION AND FUTURE WORKS}

In this paper, we have discussed whether Learning Analytics can be used to estimate learning assistance skills, based on a review of previous research. We aimed to verify whether this is possible by using log data. We found that it is possible to estimate learning assistance skills from data on learning behavior by using LAD. How should we visualize these?

For example, analyzing students' learning behaviors from log data accumulated from e-Book viewers could be beneficial for instructors and learners. (Yin et al. 2018). It can also be used to develop self-regulated learning skills. Awareness of active time management for learning planning can promote the submission of one-minute papers on time and regular reports earlier than the due date (Yamada et al. 2015).

Moreover, Chen et al. (2020b) designed a science course that aligned with the collaborative problem solving (CPS) process, collected multiple data sources, and examined them in a learning analytics approach. Specifically, they compared the results of high- and low-performing groups, taking into account CPS awareness and factors of learning motivation and learning behavior, as well as individual differences in students' learning abilities. 
However, Oi et al. (2017) reported that the findings of the educational big data were only partially replicated in a replication experiment. This result suggests that "to make effective use of learning and teaching analytics, the educational environment needs to be carefully constructed to ensure reproducibility."

In inferring learning assistance skills from these findings, the question for the future is how to build learning assistance models from the data.

\section{ACKNOWLEDGEMENT}

This research was supported by JST AIP Grant No. JPMJCR19U1, JSPS Kakenhi JP19H01716, JP20H01727, and JP21K18134, Japan

\section{REFERENCES}

Akkaraju, S., 2018. Handwriting to Learn: Embedding a Crucial Study Skill in a Gateway Science Course, Journal of Effective Teaching in Higher Education, Vol. 1, No. 1, pp. 55-72.

Beck, K. and Ralph, J., 1994. Patterns Generates Architectures. Proceedings of European Conference of Object-Oriented Programming. Bologna, Italy, pp. 139-149.

Bodorik P. et al, 1991. Deciding to Correct Distributed Query Processing. In IEEE Transactions on Data and Knowledge Engineering, Vol. 4, No. 3, pp. 253-265.

Campus, P. B., 2012. Enhancing Supplemental Instruction at Brevard Community College: A Review of Peer Tutoring, Its Effectiveness on Learning Outcomes, and the Costs and Methods of Implementation.

Chen L., Lu M., Goda Y., Shimada A. and Yamada M., 2021. Learning Analytics Dashboard Supporting Metacognition. In: Ifenthaler D., Sampson D.G., Isaías P. (eds) Balancing the Tension between Digital Technologies and Learning Sciences. Cognition and Exploratory Learning in the Digital Age. Springer, Cham.

Chen, L., Inoue, K., Goda, Y. et al, 2020b. Exploring Factors that Influence Collaborative Problem Solving Awareness in Science Education. Technology Knowledge Learning, Vol. 25, pp. 337-366.

Chen, L., Lu, M., Goda, Y., and Yamada, M., 2019. Design of Learning Analytics Dashboard Supporting Metacognition. In Proceedings of $16^{\text {th }}$ International Conference Cognition and Exploratory Learning in Digital Age (CELDA 2019), pp. 175-182.

Chen, L., Lu, M., Goda, Y., Shimada, A., and Yamada, M., 2020a. Factors of the Use of Learning Analytics Dashboard that Affect Metacognition. In Proceedings of $17^{\text {th }}$ International Conference Cognition and Exploratory Learning in Digital Age (CELDA 2020), pp. 295-302.

Colver M. and Fry, T., 2016. Evidence to Support Peer Tutoring Programs at the Undergraduate Level, Journal of College Reading and Learning, Vol. 46, No. 1, pp.16-41.

Congos, D. H., 2011. Starting Out in Community College. McGraw-Hill, Chicago.

Dakhiel, Maysoon A.; Ahmed, Somaya A., 2019 Effectiveness of a Training Program in Improving Study Skills and English Language Achievement among High School Students. Journal of Educational Issues, Vol. 5, No. 1, pp. 132-149.

Does tutoring help? a look at the literature. Review of Research in Developmental Education, Vol. 7, No. 4.

Keller, P., 2020. A Terminological Study of Peer Education in Higher Education: A White Paper prepared for the College Reading and Learning Association.

Lu, M., Chen, L., Goda, Y., Shimada, A., and Yamada, M., 2020. Development of a Learning Dashboard Prototype Supporting Meta-cognition for Students. In Companion Proceedings of the 10th International Conference on Learning Analytics \& Knowledge (LAK20), pp. 104-106.

Maxwell, M., 1990. Does tutoring help? a look at the literature. Review of Research in Developmental Education, Vol. 7, No. 4.

McNamara, D. S., 2004. SERT: Self-Explanation Reading Training. Discourse Processes, Vol. 38, No. 1, pp.1-30.

O'Reilly, T., and Sabatini, J., 2016. Using Advances in Cognitive Science to Improve Students Study Skills and Reading Comprehension. In R. Schiff and R. M. Joshi (Eds). Interventions in Learning Disabilities: Literacy Studies, 13, (pp. 139-158). Switzerland: Springer International.

Ogata, H., Oi, M., Mohri, K., Okubo, F., Shimada, A., Yamada, M., Wang, J., and Hirokawa, S., 2017. Learning Analytics for E-book-based Educational Big Data in Higher Education. In Smart sensors at the IoT frontier, pp. 327-350. Springer, Cham. 
Oi, M., Yamada, M., Okubo, F., Shimada, A., and Ogata, H., 2017. Reproducibility of Findings from Educational Big Data: A Preliminary Study. LAK '17: Proceedings of the Seventh International Learning Analytics \& Knowledge Conference, pp. 536-537.

Owatari, T., Shimada, A., Minematsu, T., Hori, M., and Taniguchi, R. I., 2020. Real-Time Learning Analytics Dashboard for Students in Online Classes. In 2020 IEEE International Conference on Teaching, Assessment, and Learning for Engineering (TALE) , pp. 523-529.

Palincsar, S. A., and Brown, L. A., 1984. Reciprocal Teaching of Comprehension-Fostering and Comprehension-Monitoring Activities, Cognition and Instruction, Vol.1, No.2, pp. 117-175.

Pintrich, P. R., Smith, D. A. F., Garcia, T., and Mckeachie, W. J., 1993. Reliability and Predictive Validity of the Motivated Strategies for Learning Questionnaire (Mslq). Educational and Psychological Measurement, Vol.53, No.3, pp. 801-813.

Poyraz, C., 2013. Investigating Distance Education Students' Study Skills, Turkish Online Journal of Distance Education, Vol. 14, No. 4, pp 69-82.

Psychology Teaching Review, Vol. 11, No. 1, pp. 53-63.

Rae, J. and Aubrey Baillie, A., 2005. Peer tutoring and the study of psychology: Tutoring experience as a learning method

Salame, I. I. and Thompson, A., 2020. Students' Views on Strategic Note-Taking and Its Impact on Performance, Achievement, and Learning, International Journal of Instruction, Vol. 13, No. 2, pp. 1-16.

Schumacher, C., and Ifenthaler, D., 2018. Features students really expect from learning analytics. Computers in Human Behavior, Vol. 78, pp. 397-407.

Sheets, R. A. ,2012. Peer Tutoring and Tutor Training: A Historical Perspective. In K. Agee and R. Hodges Handbook for Training Peer Tutors and Mentors, (pp.3-6), College Reading and Learning Association, Mason, USA.

Sheets, R. A., 1994. The Effects of Training and Experience on Adult Peer Tutors in Community Colleges (Doctoral dissertation, Arizona State University).

Shimada, A., Konomi, S. I., and Ogata, H., 2018. Real-time earning analytics system for improvement of on-site lectures. Interactive Technology and Smart Education, Vol. 15, No. 4, pp. 314-331.

Stigmar, M., 2016. Peer-to-peer teaching in higher education: A critical literature review. Mentoring \& Tutoring: Partnership in Learning, Vol. 24, No. 2, pp. 124-136.

Teasley, S. D., 2017. Student facing dashboards: One size fits all? Technology, Knowledge and Learning, Vol. 22, No. 3, 377-384.

Topping, K. J., 1996. The Effectiveness of Peer Tutoring in Further and Higher Education: A Typology and Review of the Literature. Higher Education, Vol. 32, No. 3, pp. 321-345.

Watanabe, H., Chen, L., Geng, X., Goda, Y., and Shimada, A., 2020b. Design of the Time Management Skills Acquisition System Using Learning Analytics. In Proceedings of 17th International Conference Cognition and Exploratory Learning in Digital Age (CELDA 2020), pp. 67-73.

Watanabe, H., Chen, L., Goda, Y., Shimada, A., and Yamada, M., 2021. Development of a Time Management Skill Support System Based on Learning Analytics. In Companion Proceedings 11th International Conference on Learning Analytics \& Knowledge (LAK21), pp. 241-249.

Watanabe, H., Chen, L., Shimada, A., and Yamada, M., 2020a. Toward Identification of Learning Skills from Learning Analytics Approach: A Research Review. In IEEE International Conference on Teaching, Assessment, and Learning for Engineering (TALE) 2020, pp. 807-812.

Wernersbach, B.M., Crowley, S., Bates, S., and Rosenthal, C., 2014. Study Skills Course Impact on Academic Self-Efficacy. Journal of Developmental Education, Vol. 37, pp. 14-33.

Wolfe, B., 2018. The impact of a peer-tutoring model on the academic performance of secondary students. (Doctoral dissertation).

Yamada, M., Goda, Y., Matsuda, T., Kato, H., and Miyagawa, H., 2015. The Relationship among Self-Regulated Learning, Procrastination, and Learning Behaviors in Blended Learning Environment. International Association for Development of the Information Society. 12th International Conference on Cognition and Exploratory Learning in Digital Age 2015 (CELDA 2015), pp.67-74.

Yaman, B., 2019. A multiple case study: What happens in peer tutoring of calculus studies? International Journal of Education in Mathematics, Science and Technology (IJEMST), Vol. 7, No. 1, pp. 53-72.

Yin, C., Yamada, M., Oi, M., Shimada, A., Okubo, F., Kojima, K., and Ogata, H., 2019. Exploring the Relationships between Reading Behavior Patterns and Learning Outcomes based on Log Data from E-books: A Human Factor Approach. International Journal of Human-Computer Interaction, Vol. 35, No. 4-5, pp. 313-322. 